\title{
OS MOVIMENTOS SOCIAIS E A PRODUÇÃO DE MAÇÃ AGROECOLÓGICA EM SÃO JOAQUIM, SANTA CATARINA, BRASIL
}

\author{
SOCIAL MOVEMENTS AND THE PRODUCTION OF \\ AGRO-ECOLOGICAL APPLE IN SÃO JOAQUIM, \\ SANTA CATARINA, BRAZIL
}

Felipe José Comunello ${ }^{1}$

RESUMO: O objetivo deste artigo é descrever e analisar a emergência das organizações de movimentos sociais do campo no município de São Joaquim, Santa Catarina, em especial no que diz respeito à busca por alternativas de produção agroecológicas. O fio condutor desta discussão são as redes de relações sociais que sustentam esse processo. $\mathrm{O}$ artigo discute o modo como tais redes foram formadas a partir da articulação de grupos de relacionamentos, destacadamente de vizinhança e familiares, em que participaram figuras-chaves como padres e técnicos da Empresa de Pesquisa Agropecuária e Extensão Rural de Santa Catarina (EPAGRI), em consonância com um processo mais amplo de incorporação da questão ecológica pelos movimentos sociais do campo. A partir desta discussão, realiza-se uma análise dos limites e do alcance das propostas construídas pelas organizações formadas por essas redes de movimentos sociais.

Palavras-chave: agroecologia, maçã, movimentos sociais, relações sociais.

\footnotetext{
${ }^{1}$ Pós-doutorando no Programa de Pós-Graduação em Ciências Sociais da Pontifícia Universidade Católica do Rio Grande do Sul (PUCRS), com bolsa CAPES/FAPERGS, e Doutor em Antropologia Social (PPGAS/UFRGS), Porto Alegre, RS, Brasil, e-mail: felipecomunello@yahoo.com.br. 
ABSTRACT: The aim of this article is to describe and analyze the emergence of rural social movements organizations in São Joaquim, Santa Catarina, in particular with regard to the the search for alternatives for agroecological production. The guiding thread of this discussion are the networks of social relations that underpin this process. The article discusses how such networks were formed from the articulation of relationship groups, notably neighborhood and family, attended by key figures such as priests and technicians from public company of rural extension of Santa Catarina, in consonance with a broader process of incorporation of ecological issues by rural social movements. From this discussion an analysis is made of the limits and reach of proposals constructed by organizations formed by these networks of social movements.

Keywords: agroecology, apple, social movements, social relations.

\section{INTRODUÇÃO}

Este artigo busca fazer uma reconstrução histórica das condições sociais de emergência da produção de maçã agroecológica em São Joaquim, estado de Santa Catarina. Impulsionada por movimentos sociais que tomaram a agroecologia como um projeto para a construção de um modelo de agricultura oposto ao da chamada "revolução verde", essa produção se materializou no município com a criação da Cooperativa Ecológica dos Agricultores e Consumidores de São Joaquim e Região (Econeve). A Econeve contou com cerca de trinta associados na época de sua fundação, sendo oriunda de um grupo de agricultores familiares que se formou a partir da primeira metade da década de 1990.

Essa fundação ocorreu quando alguns padres da Igreja Católica, envolvidos com a pastoral social e da saúde, articularam um grupo que realizou encontros no município e cursos de educação popular em Lages, no Centro Vianei de Educação Popular. Além de agricultores, também participavam do grupo dois agrônomos da 
Empresa de Pesquisa Agropecuária e Extensão Rural de Santa Catarina (EPAGRI) - um deles era extensionista do Escritório Local da empresa, e o outro era extensionista do Centro de Treinamentos de São Joaquim (CETREJO).

Da ação desse grupo surgiu, em 1999, a Cooperativa de Crédito Rural Credineve, hoje denominada Cresol São Joaquim. Com o crédito oferecido pela Credineve, os agricultores familiares do município, um grupo social formado por mais de 500 produtores e suas famílias, passaram a produzir ou a aumentar a produção de maçã, em uma escalada de modernização que, para a grande maioria, dura até os dias atuais. Tal fato é significativo, pois, pouco mais de vinte anos antes, o Brasil praticamente não produzia maçã, e, quando então começa a produzir, esse público não tem acesso aos financiamentos, aos incentivos fiscais e à assistência técnica oferecidos pelo Estado.

Após se estabelecerem como produtores de maçã, esses mesmos agricultores familiares são colocados frente à proposta de produzir agroecologicamente, pelo movimento que havia se originado no início do processo. Especialmente por meio da Credineve, em parceria com a Organização Não Governamental Centro Vianei de Lages e com os técnicos do Escritório Local da Epagri, uma série de cursos, experimentações e viagens foi realizada para estimular a produção agroecológica. O resultado foi a criação da Econeve.

Dentre os cerca de trinta sócios que fundaram a Econeve, apenas dez implantaram pomar agroecológico. Destes, apenas seis continuaram produzindo. Além disso, esses produtores eram todos vinculados, em maior ou menor grau, às organizações que foram criadas ou conquistadas ao longo desse processo: Cresol São Joaquim, Sindicato dos Trabalhadores Rurais, Partido dos Trabalhadores, Rádio comunitária Quebra-Gelo, Jornal Carucaca e Movimento de Mulheres Agricultoras. Enfim, é possível notar que um fundo político era comum aos produtores de maçã agroecológica de São Joaquim.

Com base nas formulações de Granovetter (1985) sobre o enraizamento social das relações mercantis e, especialmente, na ideia de que laços fracos constroem pontes entre grupos sociais (GRA- 
NOVETTER, 1973; 1983), analisam-se, neste estudo, as redes de relações sociais que sustentam esse processo. Este artigo discute o modo como tais redes foram formadas a partir da articulação de grupos de relacionamentos, destacadamente de vizinhança e familiares, em que participaram figuras-chaves como padres e técnicos da EPAGRI, em consonância com um processo mais amplo de incorporação da questão ecológica pelos movimentos sociais do campo. A partir dessa discussão, realiza-se uma análise dos limites e do alcance das propostas construídas pelas organizações constituídas por essas redes de movimentos sociais.

Esta pesquisa foi realizada por meio de entrevistas semiestruturadas em profundidade. Para escolher os entrevistados, recorreuse à amostra intencional, que consiste na escolha dos participantes de acordo com critérios relevantes para a pesquisa. Nesse sentido, foram entrevistados cinco dos seis produtores de maçã agroecológica - um casal, dois técnicos da Epagri e um técnico do Centro Vianei -, a responsável pelas vendas da Ecoserra e dois ex-produtores de maçã agroecológica. As entrevistas foram transcritas para servir à análise dos dados. Utilizou-se também como importantes fontes de informação das edições do Jornal Carucaca, editado pelos movimentos sociais de São Joaquim, e da coletânea do Boletim Pixurum do Centro Vianei, que foram gentilmente cedidas. Além disso, teve-se acesso a fotos e outros documentos, também gentilmente cedidos por todas as organizações, que auxiliaram a restituir um conjunto de informações, permitindo sua análise.

\section{O SETOR MACIEIRO EM SANTA CATARINA}

A maçã é o principal produto agrícola cultivado nos municípios de São Joaquim e Fraiburgo, desde a formação de um Complexo Agroindustrial no Setor Macieiro em Santa Catarina, que ocorreu nos anos 1970 (Schmidt, 1990). A macieira foi selecionada dentre outras frutíferas de clima temperado que estavam em teste para as regiões de Fraiburgo e São Joaquim, como o pessegueiro e a ameixeira, por exemplo. Para a implantação dos pomares de maçã, era 
necessário construir condições que permitissem superar as dificuldades de clima e de solo. No que tange ao clima, a macieira exige mais frio do que o encontrado geralmente em Santa Catarina. Os solos, especialmente na região de São Joaquim, são rasos, o que dificulta o cultivo de plantas com raízes profundas, como a macieira² ${ }^{2}$

Era preciso, também, implementar outras mudanças, como o desenvolvimento de variedades adaptadas, o uso de fertilizantes químicos solúveis e de agrotóxicos e a mecanização. Além disso, foram necessárias intervenções na organização da comercialização e de estruturas de pós-colheita, principalmente no que se refere ao armazenamento e transporte. No caso específico de São Joaquim, onde o crédito rural foi basicamente o único incentivo financeiro que estimulou e financiou a implantação dos pomares, houve necessidade de organização dos agricultores. Ao contrário disso, em Fraiburgo, os produtores eram, geralmente, empresários, que implantaram os pomares via incentivos fiscais (Schmidt, 1990).

O caso de Fraiburgo é particularmente importante para a constituição do Setor Macieiro em Santa Catarina, devido à formação da Sociedade Agrícola Fraiburgo (SAFRA). A SAFRA consistia em uma associação da família Frey de Fraiburgo com as famílias de franco-argelinos Evrard e Mahler. Essa associação é fruto de uma rede de contatos, mobilizada por esses empreendedores que tinham interesse em produzir maçã. Desde o início dos anos 1930, os Frey deslocaram-se à região para instalar serraria e extrair madeira. De 1920 em diante, a exploração de madeira constituiu a principal fonte de fortalecimento de elites locais, de enriquecimento econômico e de atração de (i)migrantes (Klanovicz \& Nodari, 2005).

Nos anos 1950, com a diminuição das florestas, a exploração da madeira tendeu a diminuir, perdendo importância econômica (Klanovicz \& Nodari, 2005; Pereira et al, 2006). Esse fato levou os Frey a procurar alternativas, conhecendo os Evrard (Klanovicz \& Nodari, 2005; Pereira et al, 2006; Brandt, 2005). Os Evrard possuíam uma vinícola com 1200 hectares e cultivos de outras frutífe-

\footnotetext{
${ }^{2}$ Solo na linguagem agronômica é a camada mais externa da superfície terrestre, que recobre as rochas. É produto do intemperismo do material de origem (rochas, restos de animais e vegetais), composto de minerais, húmus, gases e água.
} 
ras na Argélia, quando esta era colônia francesa (Schmidt, 1990). A descolonização pós-segunda guerra mundial e a guerra civil da Argélia nos anos 1950 e 1960 estimulou-os a vir para o Brasil. De acordo com Klanovicz e Nodari (2005), com o contato entre os Frey e o grupo Evrard-Mahler, em 1961 foi implantado um viveiro de mudas de macieira e outras frutas em Fraiburgo. As experiências por eles compartilhadas foram importantes para as intervenções governamentais na produção de maçã, já que demonstraram a viabilidade técnica dessa produção em Santa Catarina (Klanovicz \& Nodari, 2005; Pereira et al, 2006; Brandt, 2005; Schmidt, 1990). Desse modo, estavam colocadas duas situações que impulsionaram o setor macieiro em Santa Catarina: a queda na exploração madeireira e a demonstração da viabilidade técnica da produção de maçã.

O apoio do Estado foi crucial para a presença de outro contato dos Frey na Secretaria da Agricultura de Santa Catarina: Luis Gabriel, ligado ao Grupo Perdigão de Videira. Além disso, a substituição da maçã importada exerceu forte influência no quadro das substituições de importações que se buscava no Brasil naquela época. A produção que havia sido estimulada desde os anos 1960 não dava conta de suprir a demanda, o que levava à necessidade de um volume de importação muito maior do que o produzido no país (Quadros 1 e 2).

Quadro 01: Importação de maçãs pelo Brasil (1960 - 1969)

\begin{tabular}{|c|c|c|c|c|c|c|c|c|c|c|}
\hline \multirow{2}{*}{ País } & \multicolumn{10}{|c|}{ Quantidade/ano (toneladas) } \\
\cline { 2 - 12 } & 1960 & 1961 & 1962 & 1963 & 1964 & 1965 & 1966 & 1967 & 1968 & 1969 \\
\hline Argentina & 36.424 & 43.232 & 50.153 & 64.194 & 38.477 & 59.579 & 54.629 & 85.507 & 108.222 & 105.074 \\
\hline Canadá & - & - & - & - & - & - & 799 & 599 & - & - \\
\hline Chile & - & - & - & - & - & - & - & - & 394 & 550 \\
\hline E.U.A & - & - & - & - & - & - & 939 & 1.832 & 131 & 35 \\
\hline França & - & - & - & - & - & - & - & 38 & 4.947 & 7.978 \\
\hline Grécia & - & - & - & - & - & 4 & 44 & 22 & 178 & 241 \\
\hline Uruguai & - & - & - & - & - & - & - & 236 & - & - \\
\hline
\end{tabular}

Fonte: Centro de Informações Econômico Fiscais do Ministério da Fazenda. Adaptado de Sezerino (1982, p.89 apud Brandt, 2005, p. 30). 
Quadro 02: Produção Brasileira de Maçã (1960- 1969)

\begin{tabular}{|c|c|}
\hline Anos & Maçãs (toneladas) \\
\hline 1960 & 9.513 \\
\hline 1961 & 9.981 \\
\hline 1962 & 11.300 \\
\hline 1963 & 11.620 \\
\hline 1964 & 10.578 \\
\hline 1965 & 11.987 \\
\hline 1966 & 11.779 \\
\hline 1967 & 12.392 \\
\hline 1968 & 13.035 \\
\hline 1969 & 14.432 \\
\hline
\end{tabular}

Fonte: ETEA - Ministério da Agricultura e IBGE. Adaptado de Sezerino (1982, p.85 apud Brandt, 2005, p. 30).

Outro fator de estímulo consistiu nos incentivos fiscais. A Lei 5.106 , de 2 de setembro de 1966, permitia que até 50\% do imposto de renda da pessoa jurídica fosse aplicado em reflorestamentos e florestamentos. Esses (re)florestamentos eram realizados com pínus, mas, como a Lei previa a inclusão de frutíferas, logo foi possível realizá-los também com macieira (Pereira et al, 2006). Nesse contexto, ressalta-se, conforme Pereira et al, (2006), que os incentivos fiscais foram mais importantes do que os oriundos de outros programas que viriam logo depois. Os Frey criaram, então, em 1967, a Reflorestamento Fraiburgo e a Renar Agropastoril, para aproveitar os recursos dessa Lei em reflorestamentos e em pomares.

As primeiras iniciativas de pesquisas institucionalizadas que proporcionaram o desenvolvimento de tecnologia para os pomares de maçã são encontradas na ação conjunta do antigo Instituto de Pesquisa e Experimentação Agrícola (IPEAS) e do Programa de Fruticultura de Clima Temperado (PROFIT) ${ }^{3}$. A partir desse primeiro contato, é elaborado um projeto de pesquisas aplicadas entre a Secretaria de Agricultura de Santa Catarina e o IPEAS. Previa-se, nesse projeto, a maior concentração das atividades no eixo VideiraFraiburgo e no município de São Joaquim (Schmidt, 1990).

\footnotetext{
${ }^{3}$ O Programa de Fruticultura de Clima Temperado (PROFIT) foi criado por meio da Lei n. ${ }^{\circ} 4.263$, de 31 de dezembro de 1968, e era vinculado à Secretaria de Agricultura. Diário Oficial do Estado de Santa Catarina. Florianópolis, p. 3, 31 dez. 1968. (SCHMIDT, 1990).
} 
Como mostra Schmidt (1990), Rogério Campos foi o primeiro produtor a implantar pomar em São Joaquim, também com incentivos fiscais. Antes dele, havia plantações com variedades antigas. É importante notar, também, a participação da Reflorestamento Fraiburgo e da SAFRA já nessa primeira iniciativa de pesquisa. Cabe notar que, anteriormente ao PROFIT, foi editado em Santa Catarina o Plano Estadual de Desenvolvimento da Fruticultura (PEDF), destinado à fruticultura em geral, de modo que o cultivo da maçã passou a ganhar destaque somente adiante, já com o início do PROFIT. O PEDF foi fruto da nomeação de Luis Gabriel, ligado ao grupo agroindustrial Perdigão, em meados dos anos de 1960, quando vigorava no Brasil o regime militar. O Grupo Perdigão teve sua origem no município de Videira, vizinho de Fraiburgo. Gabriel era ligado também ao grupo SAFRA (Schmidt, 1990; Klanovicz, 2007).

A cidade de São Joaquim, identificada pelo PROFIT por conta do clima frio superior ao de Fraiburgo como local adequado para produção de frutas europeias, é contemplada pela Unidade de Pesquisa Aplicada em Fruticultura, instalada em uma gleba de terra cedida por meio da Lei Municipal n. ${ }^{\circ}$ 661, de 10 de fevereiro de 1969. Essa Unidade viria a se tornar a Estação Experimental de São Joaquim, integrada à EMPASC em 1975, denominada atualmente de Empresa de Pesquisa e Extensão Agropecuária de Santa Catarina S.A (EPAGRI) (Schmidt, 1990).

Em março de 1971, chegava a Santa Catarina o primeiro pesquisador que viria a atuar na pesquisa - Kenshi Ushirosawa - por meio de acordo de cooperação técnica entre Brasil e Japão, enviado pela Japan International Cooperation Agency (JICA). Os acordos com a JICA proporcionaram a vinda de outros pesquisadores japoneses ao Brasil, bem como a ida de brasileiros ao Japão. Na sequência, esteve no sul do país um pesquisador da universidade norte-americana Rutgers University de New Jersey - Frederic Hough (Schmidt, 1990; Klanovicz, 2007).

Vale notar o grande empenho em criar condições tecnológicas para a produção de maçã em Santa Catarina, de tal modo que Klanovicz (2007, p. 68) chama de “'espetáculo técnico' a paisagem da 
pomicultura no sul do Brasil resultante da modernização do padrão tecnológico dos anos do pós-2 ${ }^{a}$ guerra". Nesse contexto, destacam-se os empenhos dos Frey. Willy Frey foi autorizado pela Secretaria de Agricultura em 1977 a empreender convênio com pesquisadores alemães. Além disso, os Frey cederam terras e técnicos para a Empresa Catarinense de Pesquisa (EMPASC) (Schmidt, 1990).

Willy Frey e seu pai René Frey parecem ser figuras-chave na formação do setor macieiro, tal como Insull no caso da Indústria de Energia nos Estados Unidos (Granovetter, 1992). Isso se explica porque suas ações foram decisivas na relação tanto com os estrangeiros (argelinos, franceses, alemães e suíços) quanto com o Estado, principalmente com Luís Gabriel. Dentro dos grupos sociais aos quais essas pessoas (Gabriel, família Frey, franco-argelinos etc.) pertencem, surgiram os maiores blocos de empresas que produzem, processam, compram e vendem maçã em Santa Catarina. O maior deles, grupo Fischer, começou no início do século XX com a produção de suco de laranja e entrou para o setor macieiro primeiro em parceria com os Frey, para aproveitar os incentivos fiscais, e depois adquirindo o segmento do grupo Perdigão que atuava no setor (Schmidt, 1990). Depois disso, o grupo Fischer dobrou, no mínimo, sua área de produção. Há outros blocos, como a Renar Maçãs e a Agrícola Fraiburgo (esta última com atuação também em São Joaquim e Vacaria, RS).

O controle desses blocos de empresas não é mais essencialmente familiar, como nas primeiras décadas de sua formação. Tal como outros blocos do agronegócio, são controladas por grupos que estão em diferentes setores de capital (industrial, financeiro e agrário) e de atividades (ver exemplo da Fischer). Essas empresas concentram grande parte da produção e apresentam um alto grau de integração vertical (Simioni e Pereira, s/d). O caso dos pequenos produtores e das cooperativas, que se encontram na sua maioria em São Joaquim, será abordado na próxima seção. 


\section{SÃO JOAQUIM: COOPERATIVAS, PEQUENOS PRODU- TORES E AS DINÂMICAS RECENTES}

Se um viajante, ao passar pelo oeste catarinense, facilmente reconhece os reflexos da moderna agricultura nas instalações de suínos e aves, nas regiões de Fraiburgo e São Joaquim, os pomares também revelam esses reflexos ${ }^{4}$. Um viajante cuidadoso logo perceberá que existem algumas peculiaridades na moderna produção de maçã. Poderá perceber que, enquanto em Fraiburgo as grandes plantações, o movimento de trabalhadores e de caminhões e as estruturas de armazenagem, de processamento e de distribuição estão situados em uma dimensão que deixa poucas dúvidas quanto ao seu caráter de agronegócio, em São Joaquim não é possível perceber essa unicidade, já que uma gama variada de atores sociais compõe esse quadro no município.

Em São Joaquim, encontram-se iniciativas de articulação de produtores em cooperativas, uma empresa de porte médio e, também, pequenos produtores que vendem suas produções às empresas de Fraiburgo (ou Vacaria) ou a intermediários. A cooperativa Sanjo e a empresa Hiragami são de propriedade de imigrantes e descendentes de imigrantes japoneses. É basicamente com esse público que tais empresas trabalham. Outra cooperativa, a Cooperserra, foi fundada por ocasião de incentivos de organização do PROFIT (Schmidt, 1990). Recentemente, outro grupo de produtores criou a cooperativa Frutas de Ouro. As duas últimas são cooperativas nas quais os produtores, de variadas origens étnicas, possuem um contrato fixo de produção e possuem pomares com tamanho em torno de 5 hectares.

Os produtores que não fazem parte dessas cooperativas podem vender para intermediários de empresas de outros municípios. Essas empresas são a Renar Maçãs e a Agrícola Fraiburgo, que negociam com base em contratos anuais, constituindo a chamada produção consignada. Nesse caso, o produtor sabe de antemão os preços de acordo com a categoria da fruta, descontados os custos de processamento, armazenagem, transporte e administração da venda.

\footnotetext{
${ }^{4}$ As minúcias dos reflexos da moderna agricultura na paisagem e da sua interação com as sociedades de Fraiburgo, São Joaquim e Vacaria são trabalhadas por Klanovicz \& Nodari, 2005 e Klanovicz, 2007.
} 
Já com as empresas Fischer e Schio (Vacaria), o preço é definido posteriormente à realização da venda pelas empresas, que também processam, armazenam, transportam e administram a venda.

A comercialização é apresentada como o principal problema dos pequenos produtores pelo Banco Regional de Desenvolvimento do Extremo Sul (BRDE), por estes terem apenas duas possibilidades de venda, em que os compradores estabelecem os preços:

[...] venda aos beneficiadores, situação em que a remuneração da produção fica condicionada à classificação no packing house do comprador; ou aos intermediários, que compram a fruta não classificada e as revendem, inclusive para os beneficiadores. Via de regra, tanto as agroindústrias quanto os intermediários estabelecem os preços, porque sabem da deficiência de armazenagem e da dificuldade do pomicultor para vender sua produção (BRDE, 2005, p. 20).

É possível fazer uma estimativa do número de produtores que se encaixa nessas características. Dados da Associação dos Produtores de Maçã e Pêra de Santa Catarina (AMAP-SC) informam que, no município de São Joaquim, há 1078 produtores. Segundo o Departamento de Programa e Orçamentos do BRDE,

No cadastro da Associação dos Produtores de Maçã e Pêra da Região de São Joaquim, constavam, em julho de 2004, 574 produtores associados do município de São Joaquim, sendo que $82,4 \%$ declararam ter área de pomar até 5 hectares, $13,4 \%$ entre 5 e 10 hectares, $4 \%$ entre 10 e 50 hectares e apenas 1 associado declarou área superior a 50 hectares (BRDE, 2005, p. 18).

Desse modo, tomando-se como base para o conjunto dos 1078 produtores o percentual demonstrado nesse estudo, uma estimativa razoável é que, destes, $60 \%$ a $80 \%$, ou seja, entre 650 e 860 produtores utilizam uma área de até cinco hectares. Desse grupo de agricultores familiares, com até cinco hectares disponíveis para produção, uma parte começou a produzir maçã desde o início da for- 
mação do setor macieiro, mas a grande maioria entrou na produção de maçã na década de 1990, com a facilitação do acesso ao crédito, quando houve a criação da Cooperativa de Crédito Rural Credineve, atual Cresol São Joaquim. Segundo informação de um dirigente dessa cooperativa, cerca de 500 pequenos produtores implantaram seus pomares com o apoio da Cresol. Esses pequenos produtores se localizam, em sua maioria, nas comunidades de Luizinho, Estância do Meio, Boava, São Sebastião da Vargem, Lomba e Despraiado. Essas comunidades têm em sua origem pessoas que, desde o início do século XX, encontravam trabalho nos sucessivos "ciclos econômicos" que a região conheceu (madeira e pecuária), nas áreas que, pela presença de floresta e relevo acidentado, não foram aproveitadas como pastagens nos domínios das grandes propriedades.

Com o fim do chamado "ciclo da madeira", ocorrido entre os anos de 1940 a 1970, muitos moradores dessas comunidades que haviam trabalhado nas serrarias permaneceram no local. Até meados dos anos 1990, sua produção esteve baseada principalmente em culturas como batata, feijão e milho e na criação de animais (bovinos e suínos) direcionados para o consumo próprio e/ou para o comércio local e regional. Como notou Pereira (2004), diferentemente de outras comunidades da região, nessas os agricultores passaram a produzir maçã nos anos 1990 com base em um processo organizativo. Uma década depois, começa a produção de maçã nessas comunidades, tendo os agricultores familiares possibilidade de acessar uma condição de vida diferente da que tinham antes, que era mais marginalizada em comparação a de grupos sociais mais capitalizados.

Iniciado com a criação da Credineve, o processo organizativo no qual esses agricultores familiares se envolveram, em diferentes intensidades, resultou na formação de outra cooperativa de produtores de maçã: a Cooperativa Ecológica dos Agricultores e Consumidores de São Joaquim e Região (Econeve). A Econeve surgiu em 2001 e é fruto da ação de movimentos sociais, principalmente de um grupo vinculado à Igreja Católica. Está alicerçada na proposta de produzir maçã sem o uso da tecnologia e dos demais preceitos oriundos da modernização da agricultura. Além disso, pode ser con- 
siderada uma resposta às crescentes exigências por uma produção que não agrida o ambiente e a saúde humana, que passou a ganhar grande relevo nas estratégias dos atores sociais do setor macieiro desde a última metade dos anos 1980 (Klanovicz, 2007). Porém, sua formação dá-se fundamentalmente em tensão com a tendência dominante do setor macieiro em responder a estas exigências, que se materializa na Produção Integrada de Maçã (PIM).

Para situar essa tendência dominante é importante levar em conta que o setor macieiro é influenciado por dinâmicas globais. A análise de Cadeia Global de Valor (GVC), que pode ser entendida como uma metodologia para estudar a governança econômica global, é útil para compreender o desenrolar disso5. Para o Brasil, na GVC da maçã, as normalizações em torno das exigências de qualidade ambiental adquiriram um lugar importante nas últimas décadas. Um desfecho relevante desse processo veio a ocorrer no início dos anos 2000, quando "compradores europeus convencionaram a não possibilidade de exportação de maçãs para a União Européia-EU, a partir de 2003, se produzidas em sistema convencional" (Andrigueto e Kososki, 2004). Com isso, são dois processos que ocorrem concomitantemente, com influências mútuas: o aumento das exportações de maçãs brasileiras e o ajuste às exigências ambientais.

No que tange à queda das importações e ao aumento das exportações de maçã, é na segunda metade da década de 1990 que isso ocorre. Como mostra Fioravanço (2009, p. 57), até 1996 essas quantidades vinham oscilando, quando então o Brasil atingiu o recorde de importação de maçã: 257.142 toneladas. Mas, é somente a partir de 1999 que as exportações brasileiras ganham expressão, chegando a atingir o recorde de 153.043 toneladas em 2004 (Figura 01). As estimativas do CEPA/Epagri, com base nos dados do Ministério do Desenvolvimento, Indústria e Comércio Exterior (MDIC/Secex), são de que,

\footnotetext{
${ }^{5}$ As análises de GVC têm sublinhado o papel de companhias poderosas, chamadas de firmas líderes (lead firms) na governança econômica global. Para Gibbon et al (2008. p. 316 [tradução nossa]), a análise de GVC “concebe as firmas líderes como atores centrais em um sistema segmentado de governança econômica global”. Segundo os autores, uma forma de abordar a coordenação é tratá-la como normalização, que seria projetar o realinhamento de uma dada prática para que ela reflita ou materialize um standard ou uma norma. A abordagem analisa tanto o ambiente normativo imediato quanto as amplas estruturas que influenciam as designações embutidas em produtos e serviços.
} 
em 2007 e 2008, mantiveram-se em torno de 112,1 mil toneladas as quantidades exportadas de maçã, sendo 95\% dos negócios realizados com países da União Europeia. Essa quantidade, próxima a 10\% da produção nacional, segue para a Europa após cumprir as exigências determinadas quantos às características qualitativas dos produtos.

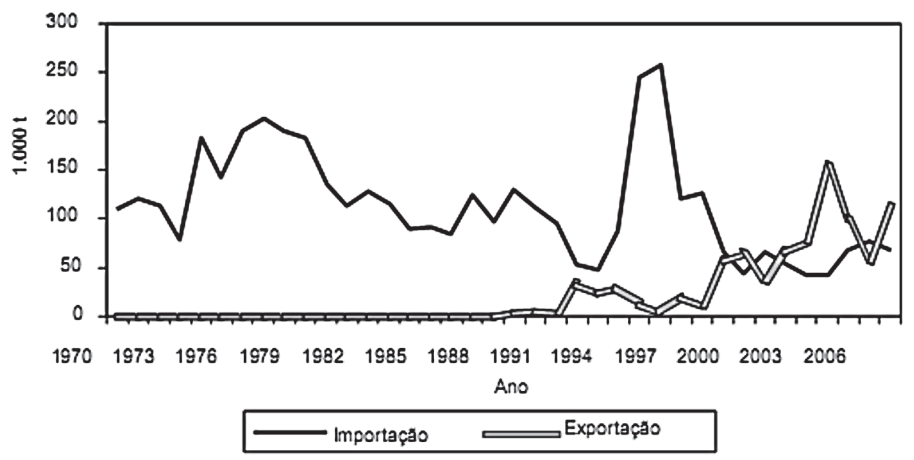

Figura 01 - Evolução da Importação e Exportação Brasileira de Maçã, Período 1970 a 2007. Fonte: FAO (2008) e IBRAF (2008) apud Fioravanço (2009, p. 58).

As grandes empresas já capitaneavam ajustes de qualidade próprios, como é o caso da Fischer, especialmente em ligações com redes varejistas transnacionais ${ }^{6}$. Contudo, é com o desenvolvimento do programa de Produção Integrada de Frutas (PIF) pelo Ministério da Agricultura (MAPA) que essas normas vão se espraiar para o conjunto do setor. Isso pode ser verificado na afirmação de Andrigueto e Kososki (2004), de que é prioridade estratégica elevar os padrões de qualidade e competitividade da fruticultura brasileira nos mercados internacionais com base no sistema de produção integrada. Esses dois autores são vinculados ao Programa de Desenvolvimento da Fruticultura (PROFRUTA) e ao projeto de Avaliação da Conformidade da Produção Integrada de Frutas do MAPA.

Com isso, o sistema de produção integrada passa a figurar no centro da estratégia para alavancar a exportação de maçãs brasileiras, capitaneada pelo MAPA. Prova disso é que o sistema de produção integrada, enquanto parte do PROFRUTA, foi incluído no

${ }^{6}$ Esta empresa possui uma série de certificados de qualidade, como Garantia de Origem Carrefour (GO) e Tesco Nature's Choice (TNC). 
Plano Plurianual 2000/2003 como prioridade estratégica do MAPA. Visto de outro ângulo, é possível afirmar que, em alguma medida, as exigências de qualidade contidas no sistema integrado tendem a repercutir no setor como um todo, pois é possível perceber que quem exporta com o sistema integrado pertence aos mesmos grupos sociais daqueles que produzem no restante do setor, que é chamado por muitos de sistema convencional. O sistema de produção integrada de maçã está envolto em uma ação mais ampla para modificar os sistemas de produção com vistas à exportação. Em 2002, foi lançado o Marco Legal que instituiu as diretrizes, as normas e os regulamentos para o sistema de Produção Integrada de Frutas (PIF), editado pelo Ministério da Agricultura, Pecuária e Abastecimento (MAPA) em parceria com o Instituto Nacional de Metrologia, Normalização e Qualidade Industrial (INMETRO) e com o Conselho Nacional de Desenvolvimento Científico e Tecnológico $(\mathrm{CNPq})$. A produção de maçã foi a primeira a ter normas e selo específicos definidos. O texto inicial da Instrução Normativa n. ${ }^{\circ}$ 20, de 27 de setembro de 2001, explicita o objetivo do sistema, que é atender à demanda crescente por produtos que respeitem o ambiente, como se vê no trecho a seguir:

[...] a crescente demanda por alimentos de qualidade depende de sistemas produtivos seguros e não agressivos ao meio ambiente, e que a regulamentação desses sistemas assegure a identificação da origem do produto e a rastreabilidade dos processos adotados ao longo da cadeia produtiva das frutas (Andrigueto, 2001).

Antes disso, em 1996 a Embrapa Uva e Vinho, de Bento Gonçalves, iniciou um processo de discussão de conceitos e normas com agentes privados e instituições públicas, com base no estabelecido desde a década de 1970 na Europa como Produção Integrada (PI) ${ }^{7}$.

\footnotetext{
${ }^{7}$ Os antecedentes da PI são os desenvolvimentos em torno do controle biológico, que têm impulso com a criação, em 1956, da Organização Internacional para o Controle Biológico (OILB). Em uma publicação de revisão histórica da organização, os autores retratam seu caráter da mesma, como se percebe neste trecho: "A missão da OILB é promover o desenvolvimento do controle biológico e sua aplicação em programas de controle integrado, onde controle biológico significa o uso de organismos vivos ou seus produtos para prevenir ou reduzir perdas ou danos causados por organismos pragas (ou, em resumo, o uso de biota para controlar biota) (Boller et al. 2006)".
} 
Segundo a pesquisadora Rosa Sanhueza ${ }^{8}$, no início de 1998 a Embrapa Uva e Vinho, a EPAGRI, a Universidade Federal do Rio Grande do Sul (UFRGS), o Instituto Biológico de São Paulo e a Associação Brasileira de Produtores de Maçã (ABPM) definiram cinco áreas localizadas nos três municípios mais importantes de produção da fruta (Vacaria, RS; Fraiburgo, SC; e São Joaquim, SC), em que são encontradas as cultivares Gala e Fuji, para iniciar a comparação entre o Sistema Integrado e o Convencional de produção de maçãs. Em cada local, áreas de 3,4 a 6,4 hectares foram implantadas para cada variedade e sistema de produção, totalizando 100 hectares de área sob avaliação.

A partir do lançamento do Marco Legal, o Instituto Nacional de Metrologia, Qualidade e Tecnologia (Inmetro) passou a acreditar Organismos de Avaliação da Conformidade (OAC), instituições que, ao atenderem os requisitos, tornam-se responsáveis pela fiscalização dos produtores e empacotadores. Isso significa que está prevista na PIF a fiscalização das operações de produção nos pomares e nos packing houses. As diretrizes específicas para a Produção Integrada de Maçã (PIM) definem os ajustes que devem ser feitos nas operações de produção. Foi publicado um caderno de campo para os produtores e um caderno de pós-colheita para os empacotadores, no qual deve ser registrada a execução das operações. A cada safra, é disponibilizada uma grade de agroquímicos permitidos para uso, atualizada periodicamente, dentre os quais estão incluídos: inseticidas, acaricidas, fungicidas, herbicidas e fertilizantes. A adequação a esses procedimentos permite a emissão de um selo com a marca PIM, que permite o rastreamento da fruta por meio da numeração impressa.

Os dados disponíveis sobre a implementação da PIM aparentemente não são muito consolidados. De acordo com Ribeiro (2005), com base no Anuário da Fruticultura Brasileira de 2004, havia, nesse ano, 211 produtores, com uma produção de 461.860 toneladas em 13.196 hectares. Segundo o Anuário (2008, p. 44), "na região Sul, no polo de produção de maçã, aproximadamente $60 \%$ da área cultivada adota o sistema”. Conforme Andrigueto e Kososki (2004), “os

\footnotetext{
${ }^{8}$ História da Produção Integrada de Frutas no Brasil. Rosa Maria Valdebenito Sanhueza. http:// www.cnpuv.embrapa.br/publica/artigos/historia.html Acesso em 09/04/2009.
} 
Indicadores parciais de racionalização do uso de Agrotóxicos 2003 para a PIM são de $40 \%$ em inseticidas, $15 \%$ em fungicidas, $67 \%$ em acaricidas e $67 \%$ em herbicidas".

Em São Joaquim, são principalmente os imigrantes e descendentes de imigrantes japoneses que aderiam à PIM. Oficialmente, estão cadastrados na página do Inmetro 20 produtores. Os dados quanto à área e quantidade de produção indicam uma média de 10 hectares e 400 toneladas por produtor, exceto para o caso de $\mathrm{Fu}-$ mio Hiragami, que, de acordo com os dados do Inmetro, produz em 193,33 hectares 6051 toneladas processadas em sua própria empresa.

São três as empacotadoras de São Joaquim que aderiram à PIM, cadastradas na página do Inmetro: Sanjo, Cooperserra e Hiragami. A Sanjo apresenta em seu cadastro 28000 toneladas de maçã, das quais 27500 são destinadas à exportação. A Cooperserra tem cadastradas 1664 toneladas, das quais 1464 são para o mercado interno. A Hiragami, por sua vez, tem cadastradas 5640 toneladas, com o destino especificado para os estados de São Paulo, Paraná, Santa Catarina e Minas Gerais. Com base nesses dados, pode-se perceber que as empacotadoras têm em seu cadastro o dobro de toneladas de maçã em comparação ao que está nos cadastros dos produtores. Tal fato denota certa incongruência de informações, mas é importante notar a indicação de que a grande maioria da produção cadastrada na PIM está direcionada para exportação, confirmando o argumento levantado nesta seção.

\section{4 "UMA ANDORINHA SÓ NÃO FAZ VERÃO”: A FORMAÇÃO DA REDE DE MOVIMENTOS SOCIAIS EM SÃO JOAQUIM, SC}

A Cooperativa Econeve foi fundada em 2001 por um grupo de agricultores familiares, produtores de maçã. A história da Econeve confunde-se com a história da Cooperativa de Crédito Credineve, atualmente Cresol São Joaquim, que foi fundada pelo mesmo grupo dois anos antes. A Cresol, hoje bastante conhecida em boa parte dos municípios do sul do país, era criada naquele momento para ser uma alternativa de acesso ao crédito a agricultores familiares. Os bancos 
tradicionais não tinham os pequenos agricultores como seus clientes preferenciais e o Programa Nacional de Fortalecimento da Agricultura Familiar (PRONAF) dispunha de recursos a este público, que teve acesso a eles por meio da Credineve, na época, da Cresol São Joaquim, atualmente. Foi a ocasião para que articulações de movimentos sociais pudessem vir à tona.

Em São Joaquim, a inauguração da Cooperativa de Crédito Rural de São Joaquim (Credineve) foi o marco fundamental para as organizações dos movimentos sociais que viriam em seguida, dentre as quais estava a Econeve. "Uma andorinha só não faz verão", sentenciava uma das matérias do caderno especial do Jornal Mural de São Joaquim, de janeiro de 1999 (edição especial), dedicado a noticiar a inauguração da Credineve, que ocorreu em 11 de janeiro. O momento foi de festa, tanto para a comunidade, que finalmente ganhava sua Cooperativa, quanto para os agricultores da região, que finalmente iriam poder usufruir de um serviço de crédito rural exclusivamente destinado a eles 9

A matéria também relata a posse do Conselho Diretor (com os respectivos membros), a inauguração e a bênção da sede pelos Padres Blévio e Edson (Figura 01) e um coquetel no principal clube da cidade com a presença de mais de 600 pessoas. Esse conjunto de rituais é significativo para revelar algumas características da formação da nova instituição de crédito e do que se seguiu com a fundação da Econeve. Nesse sentido, a bênção da sede revela a importância da participação da Igreja Católica, e o coquetel de "abertura de portas" representa o apoio por meio do patrocínio de organizações e pessoas de características diversas e delimita uma separação entre apoio e parceria.

Dentre os "apoiadores", encontra-se o leque diverso de diálogo estabelecido pelos envolvidos na Cooperativa, abrangendo desde lojas de produtos agropecuários, tratores e equipamentos agrícolas até a cooperativa de produtores de maçã (convencional) Cooperserra; de oficina mecânica, posto de combustíveis e loja de automóveis a vereadores e demais pessoas físicas. Dentre esses apoiadores, figuram

\footnotetext{
${ }^{9}$ Credineve inicia atividades com 140 associados: Credineve tem o apoio das várias cooperativas singulares agregadas ao sistema Cresol Baser. Jornal Mural, São Joaquim, Janeiro de 1999, Caderno Especial Credineve, p. 2.
} 
pessoas que podem ser consideradas "parceiros", como Elvio Antonio Peruchi e Nilton Nunes de Jesus, agrônomos extensionista da Epagri.

Dentre as "parcerias", estão apoiadores mais permanentes, envolvendo: parceiros no âmbito do modelo de crédito oferecido, como as demais cooperativas do sistema Cresol Baser - as Cooperativas Integradas da Região Sul; parceiros na viabilização das operações financeiras, como o Banco do Brasil, pois a Cresol necessita de uma conta nesse banco para que esteja vinculada ao sistema bancário nacional; parceiros na disponibilização de técnicos e outros tipos de apoios locais, como a Epagri e a Prefeitura Municipal de São Joaquim; parceiros nas relações com as comunidades, como a Igreja Católica, a Pastoral da Saúde e os Conselhos Comunitários; e parceiros na formação técnica e na construção de políticas, como as ONGs Cepagro e Instituto Vianei.

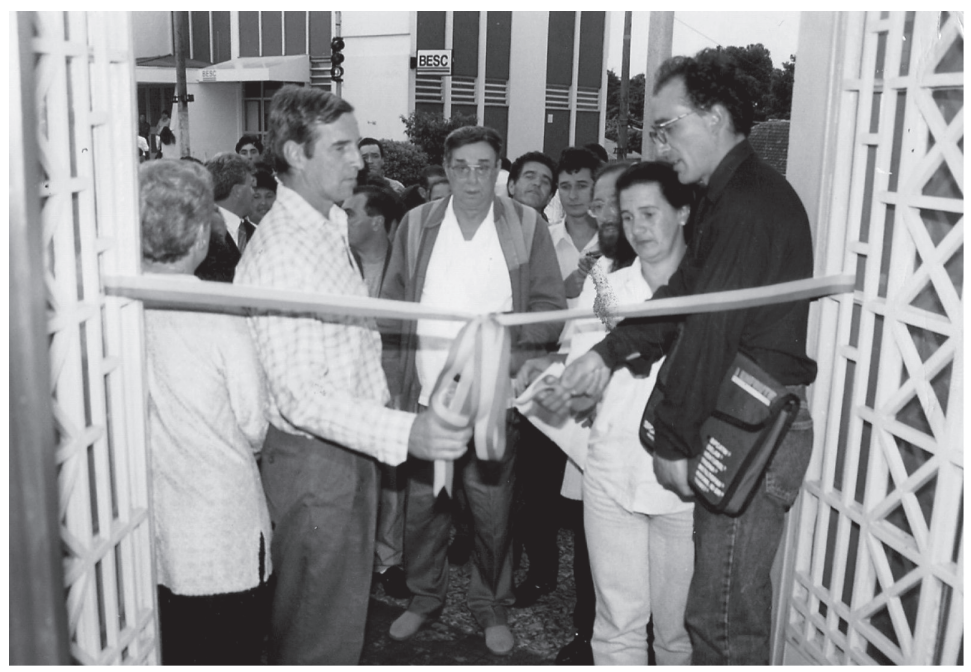

FIGURA 02. Inauguração e bênção da sede da Credineve. Fonte: Arquivo Cresol São Joaquim.

Os padres da Igreja Católica tiveram papel-chave nesse processo, como foi constatado nas entrevistas diretas realizadas nesta pesquisa, em que pode ser verificado que os mesmos, além de ser líderes espirituais - papel que lhes é conferido a priori por sua posição de portadores da mensagem da doutrina religiosa - podem ser articuladores sociais. Certamente, os papéis são interdependentes, 
pois a liderança espiritual dispõe de um carisma que lhe favorece a aproximação com as pessoas e vice-versa. Tendo em vista as proposições de Granovetter (1973), pode-se inferir que, dessa maneira, os padres estabeleceram "laços fortes" com membros de comunidades diferentes, o que permitiu a formação de novos laços sociais, pois os padres proporcionavam a criação de pontes dentro da rede de movimentos sociais de São Joaquim entre seus contatos "laços fracos". Quanto a isso, Granovetter (1973) assinala que, em grandes redes, é raro que haja um caminho apenas, embora os caminhos mais curtos possam ser os preferenciais e mais eficientes. Em outras palavras, os padres eram a forma mais simples para que pessoas de distintas redes de relacionamentos (familiares, amigos e vizinhos, por exemplo) pudessem se conhecer e constituir novas redes, como foi do que, neste trabalho, é chamado de rede dos movimentos sociais em São Joaquim.

Com isso, os padres proporcionaram a ocasião para que pessoas de comunidades diferentes pudessem discutir temas de interesse comum. Assim foi, por exemplo, com Antonio Moreira ${ }^{10}$, uma vez que sua inserção na formação da Credineve

(...) foi através da pastoral social, o Padre Elias Wolf, ele incentivava os encontros... ele incentivava através dos espaços que existe na igreja, a pastoral social que era um espaço, a organização de grupos pra discutir problemas no meio rural. Foi levantada duas questões, que era o sindicalismo e a questão do crédito. A partir daí foi feito dois ou três encontros e se definiu trabalhar mais a questão do crédito... porque esses encontros surgiram em 1993... 93 e 94.

Nessa entrevista do primeiro presidente, verifica-se que a organização de grupos era uma prática usual nos encontros. Eram nos grupos que se discutiam os temas em evidência, principalmente o sindicalismo e a questão do crédito, e em que se definia qual questão seria a mais trabalhada.

Uma participante da diretoria da Cresol, na época em que a pesquisa de campo foi feita, também participou desses encontros.

\footnotetext{
${ }^{10}$ Esse e os demais nomes de produtores são fictícios. Os nomes de técnicos da Epagri e de ONGs e padres da Igreja Católica foram mantidos.
} 
Segundo ela, o grupo passou por um período de estudos da "história do povo serrano", para, então, "fazer alguma coisa". No início, o grupo descartou a hipótese de disputar o sindicato, pois entendeu que não era a hora. No entanto, de acordo com o que foi até aqui exposto, pode-se inferir que a disputa do sindicato e a criação de uma cooperativa estavam no horizonte dos componentes do grupo. E a formação da cooperativa, antes de disputar o sindicato, é notada por Dona Mariana como um caso diferenciado do que aconteceu com as demais Cooperativas do Sistema Cresol.

A história da Cresol ela é diferente de outros lugares. Por que quase todas as Cresol surgiram a partir de sindicatos né. E aqui em São Joaquim foi o inverso, a Cresol que começou trabalhar pra ganhar esse sindicato.

Esse foi o caso da Credicarú, a qual teve, em sua formação, importante participação do Sindicato de Trabalhadores Rurais do município, que há muito se articulava com o Centro Vianei. O trecho da entrevista de Mariana, recém transcrito, coloca em questão como foi o processo de decisão do grupo por construir primeiro a Credineve e depois procurar o envolvimento com o sindicato. O que é importante notar é que a formação da Credineve ocorreu a partir da articulação de uma rede, em que pessoas com interesses comuns vieram a se conhecer e formar "laços fortes" a partir de pontes proporcionadas por "laços fracos". Essa é a importância dos "laços fracos" na formação da rede de movimentos sociais em São Joaquim, que vieram posteriormente buscar espaço nos mercados agroecológicos, em que também "laços fracos" foram importantes, como será discutido a seguir.

\section{A REDE DE MOVIMENTOS SOCIAIS DE SÃO JOAQUIM, SC, E OS MOVIMENTOS DE AGROECOLOGIA}

Os movimentos de agroecologia são permeados por redes sociais ${ }^{11}$. Tais redes têm grupos sociais e políticos de importância

\footnotetext{
${ }^{11}$ Como argumenta Almeida (2002), não há um movimento social organizado que constitui a agroecologia como um todo. Há, porém, movimentos organizados que constituem a agroecologia; por isso, é utilizado o termo movimentos de agroecologia.
} 
considerável. Na região de São Joaquim, município onde foi fundada a Econeve, foi criado nos anos 1980 o Centro Vianei, um importante grupo de agentes que vieram a se envolver com a agroecologia ${ }^{12}$.

Existiram diferentes arranjos regionais da rede Projetos Tecnologias Alternativas (PTA), entre as ONGs que a compunham ${ }^{13}$. Nos anos 1990, com a incorporação do termo agroecologia, ocorreu também a ampliação da atuação desses grupos (Luzzi, 2007). Nesse processo, segundo Natal, técnico do Centro Vianei, considera-se que, "no caso do sul, a sucedânea da PTA é a Rede Ecovida"14. Destaca-se que, desde então, ocorreu uma incorporação de organizações de agricultores familiares e camponeses a essas articulações (Luzzi, 2007).

Nessa trama é que o grupo que havia formado a Credineve passa a buscar a agroecologia, pois estavam envolvidos com o Centro Vianei, um dos principais protagonistas do movimento agroecológico no país. Logo após o técnico Elvio Peruchi da Epagri também se envolveria com o tema. Esses "laços fortes" foram os que levaram o grupo a encaminhar suas predisposições para a construção de uma proposta de agroecologia em São Joaquim, materializada na produção de maçã agroecológica, com a criação da Cooperativa Econeve.

Vários entrevistados relataram que, nos cursos de educação popular realizados pelo Centro Vianei, um dos temas abordados era a agroecologia. Em parte devido a essa bagagem e em parte devido às experiências que passaram a ser conhecidas, o grupo que estava dirigindo a Credineve passou a estimular o que foi chamado de "conversão dos cultivos realizados pelos associados para forma agroecológica de produção". Essa afirmação consta em um trecho da ficha de inscrição da experiência “Organização da Agricultura Familiar para o Desenvolvi-

\footnotetext{
${ }^{12}$ Esse relacionamento tem início quando a experiência do Centro Vianei foi escolhida para ser acompanha pelo PTA/FASE em um seminário do projeto em 1983 (Dias, 2004; Luzzi, 2007). Com o PTA/FASE, diversas organizações articulam-se em vários estados do país em torno de troca de experiências sobre pesquisas e ações de propostas alternativas de produção ao modelo oriundo da modernização da agricultura. Alguns profissionais que estavam vinculados ao projeto PTA/FASE criaram a ONG AS/PTA em 1989, logo após esse projeto ser desvinculado da FASE (Dias, 2004).

${ }^{13}$ Segundo Dias (2004, p. 133), no sul do país, em um primeiro momento, agruparam-se, além do próprio Centro Vianei, o Centro de Tecnologias Alternativas Populares (CETAP), do Rio Grande do Sul, a Rede de Intercâmbio do Paraná, a Fundação para o Desenvolvimento Econômico-Rural para o Centro-Oeste do Paraná (RURECO) e a Associação de Estudos, Orientação e Assistência Rural (ASSESSOAR).

${ }^{14}$ Natal João Magnanti. Entrevista concedida ao autor em 18/09/2009.
} 
mento Rural Sustentável no município de São Joaquim, estado de Santa Catarina", no primeiro Encontro Nacional de Agroecologia, realizado no Rio de Janeiro em $2002^{15}$. Participaram seis pessoas, incluindo Elvio Peruchi e Amadeu Bernardes, representando a Credineve, e Dona Mariana, na época representando o movimento de mulheres.

Dias (2004) argumenta que, apesar de ser cedo para afirmar, o Encontro Nacional de Agroecologia (ENA) poderia chegar a ser visto como um divisor de águas na trajetória da Assessoria e Serviços - Projetos Tecnologias Alternativas (AS-PTA). Isso poderia ser aplicado ao conjunto da rede PTA, pois esta tem relação muito próxima com a AS-PTA. Nesse sentido, Luzzi (2007) argumenta que o ENA foi o momento em que se iniciou um novo tipo de articulação entre os integrantes do que tinha sido a rede PTA e os novos atores, principalmente agricultores vinculados aos movimentos sociais ${ }^{16}$.

É desse o conjunto que participa o grupo de São Joaquim. A experiência por eles apresentada no ENA demonstra o modo como procuravam caracterizar o processo. Mas, acima de tudo, é resultado de ações anteriores de investimento do grupo na agroecologia e referência para ações posteriores. Boa parte dos primeiros compradores de fora de Santa Catarina foram conhecidos nesse encontro, os quais são aqui considerados como "laços fracos". No período anterior, que é praticamente o período de formação da Econeve, o técnico Elvio Peruchi emergiu como a figura-chave de articulação da agroecologia nas reuniões em comunidades, capacitações e visitas a outras experiências.

Um dos entrevistados, Amadeu Bernardes, quando perguntado sobre o que o motivou a produzir maçã agroecológica, lembra Peruchi como um visionário: "Foi as idéias do Peruchi que, ele vamos dizer assim, era um visionário, enxergava um pouco mais longe do que nós os agricultores aqui". Para outra entrevistada, Dona Mariana, Peruchi "era o grande sonhador".

Se ele tinha uma capacidade de antecipar as oportunidades ou era um sonhador, isso não pode ser respondido aqui. No entanto,

\footnotetext{
${ }^{15}$ Disponível em http://www.encontroagroecologia.org.br/files/SC_308.rtf - acesso em 21/09/2008.

${ }^{16}$ No I ENA, foi criada a Articulação Nacional de Agroecologia (ANA), que passou a articular ONGs, movimentos sociais e outras entidades. Para maiores detalhes sobre o ENA e a ANA, ver Dias (2004) e Luzzi (2007).
} 
essas declarações ilustram a importância de sua atuação no início da produção agroecológica em São Joaquim. Seu colega Nilton afirma, também, que, depois de muito tempo trabalhando com a produção de maçã convencional, Peruchi resolveu parar com o trabalho de assistência que prestava a essa produção.

Isso aconteceu após a criação da Credineve, quando Peruchi e Nilton foram responsáveis pela conversão de um pomar do Centro de Treinamentos da Epagri de São Joaquim (Cetrejo) para a agroecologia, já que eram unidades didáticas, não direcionadas à geração de renda econômica, em que era possível experimentar. Nilton, então extensionista do Escritório Local da Epagri, na época estava locado no Cetrejo. Segundo ele, nesse pomar foram feitos os primeiros testes de produção e treinamentos com os agricultores, incluindo a fabricação de calda bordalesa, um dos principais produtos usados na agroecologia. Segundo Nilton,

As primeiras reuniões davam mais de 50 produtores. Acho que teve uma reunião que se não me engano deu 70 produtores. Muitos japoneses foram lá de curioso, no primeiro dia de campo que nós fizemos pra avaliar e tal.

Nilton narra, também, uma sequência de cursos que realizava com figuras conhecidas na agroecologia, como os pesquisadores da Universidade da Califórnia, Berkeley, nos Estados Unidos, Miguel Altieri e Clara Nichols, em uma de suas passagens por Santa Catarina, e Delvino Magro, agricultor de Ipê, RS, criador do fertilizante Super Magro e um dos primeiros produtores de maçã agroecológica no seu estado. O município de Ipê foi visitado pelos agricultores de São Joaquim e de lá muitos ensinamentos foram levados. Ressaltase, ainda, que os técnicos do Centro Vianei ministraram vários cursos para os agricultores que se interessaram pelo assunto.

Essa circulação de informações entre os participantes nos cursos, nas viagens, nas conversas e nas demonstrações práticas foi estimulando as pessoas a produzir maçã agroecológica. Em grande parte, essas ocasiões eram propícias para diversas possibilidades de 
contato com "laços fracos". Entretanto, outras dificuldades fizeram com que apenas nove agricultores resolvessem produzir de fato, o que indica que não basta apenas ter "laços fracos". Esses nove agricultores, associados a interessados em produzir batata agroecológica ou apenas a apoiar, chegando a um total de 32 pessoas, fundaram a Econeve, em 2001, depois de cerca de um ano de reuniões com vistas a acertar as condições de funcionamento.

A criação da Econeve foi acompanhada de perto pela Credineve, tanto do ponto de vista material quanto imaterial. No plano material, linhas de crédito e assistência técnica, por meio de um agrônomo, eram oferecidas aos produtores agroecológicos. Além disso, muitos cursos e viagens tiveram o apoio direto do financiamento da Credineve. No plano imaterial, desde o início, a agroecologia fez parte do conjunto de conteúdos que informaram a ação das pessoas que estavam na Credineve.

Segundo o agrônomo contratado pela Credineve na época, Marcos Martini ${ }^{17}$, em entrevista direta, cerca de 30 pessoas tentaram produzir maçã agroecológica. Mas as primeiras produções foram praticamente perdidas, por motivos que se correlacionam: falta de mercado para venda, falta de controle para a sarna da macieira e a mosca das frutas e menor produtividade da maçã agroecológica em relação à convencional.

Não é possível afirmar se as perdas dos primeiros pomares foram suficientes para desanimar um número maior de produtores a continuar atuando na produção de maçã. Contudo, é fato que outros produtores que tentaram produzir tiveram de recorrer ao uso de controle químico para a sarna da macieira e da mosca da fruta a fim de não comprometer o rendimento. Os que não o fizeram tiveram de contar com outras rendas nos primeiros anos de produção. Conforme Callon (1997), esses imperativos traduzem, entre outras coisas, necessárias relações dos produtores (nesse caso, os que necessitam das técnicas da agroecologia na sua produção) com os mercados, indicando, muitas vezes, barreiras que precisam ser ultrapassadas para a continuidade do projeto de produção.

Para quem deseja produzir maçãs sem o uso de inseticidas químicos, como é o caso da produção agroecológica, do ponto de

${ }^{17}$ Nome fictício. 
vista das técnicas de produção a presença da mosca-das-frutas torna-se o principal obstáculo ${ }^{18}$. Ainda não se conhecem métodos biológicos que possam evitá-la, seja por meio de predadores, repelentes ou caldas, nem métodos culturais, como plantas de contenção, por exemplo. O único método eficiente é o ensacamento do fruto, realizado com sacos específicos e logo no início do seu desenvolvimento. Esse método, no entanto, envolve um aumento considerável nos custos de produção, pois requer mais trabalho para efetuar a colocação dos sacos. Diante disso, uma saída é vender as frutas que foram picadas por moscas para a indústria, principalmente de vinagre, o que implica vendê-las a um preço mais baixo.

Essa situação foi a principal responsável para que a grande maioria dos agricultores familiares de São Joaquim não chegasse sequer a testar a produção agroecológica e para que muitos dos que testaram desistissem. Embora seja possível que haja safras em que a presença da mosca não prejudique a produção, em geral isso não ocorre. Além disso, a forma de lidar com esse problema é objeto de controvérsias técnicas, opondo interlocutores da moderna ciência (convencional e PIM) a agroecologistas. As pragas, em princípio, não são vistas como tais pelos agroecologistas, mas sim como seres com os quais é preciso estabelecer um convívio, do mesmo modo que as ervas daninhas devem ser encaradas como ervas espontâneas (ou outras denominações que também procuram se referir ao convívio necessário entre distintos seres em um mesmo ecossistema).

As controvérsias a respeito das formas de controle das pragas geralmente se realizam em debates que envolvem o parecer de um técnico sobre o tema. Os pareceres, feitos por engenheiros agrônomos e outros profissionais que elaboram as técnicas ou "que participam em uma fase ou outra de seu desenho, desenvolvimento e difusão, constantemente constroem hipóteses e formas de argumentação que os colocam no campo de análise sociológico (Callon, 1997, p. 83

\footnotetext{
${ }^{18}$ Há, em geral, menor produtividade na produção agroecológica, principalmente por motivos relacionados à adubação e ao adensamento de plantas. Contudo, essa menor produtividade pode ser compensada com razoável satisfação pelo preço e por motivos relacionados à saúde, ao ambiente etc. A mosca-das-frutas é também um dos principais obstáculos para outras frutíferas cultivadas em sistemas semelhantes ao que está sendo discutindo neste estudo.
} 
[tradução nossa])". Esses técnicos, que Callon (1997) chama de engenheiros-sociólogos, atuam na introdução de uma inovação tecnológica, procurando alinhar esta a outros atores que possam apoiá-la, como órgãos de governos, movimentos sociais etc.

Com as técnicas de produção agroecológicas, isso pôde ser visto quando, em determinado momento, chegou-se a ter a impressão de que o principal obstáculo a ser controlado seria a sarna da macieira, causada por um fungo (Venturia inaequalis) e não a mosca-das-frutas. Com isso, vê-se aqui uma marca da heterogeneidade de componentes com os quais lidam os engenheiros-sociólogos. Isso era algo que estava presente desde os primeiros testes realizados no pomar experimental do Cetrejo. Como relata o então técnico da Epagri lotado nessa unidade, Nilton Nunes de Jesus, os que procuravam saber dos resultados tinham como curiosidade

(...) principalmente a questão da sarna. Se dizia que a sarna era o principal problema. Na verdade não era. Sarna era fácil de controlar no sistema orgânico. O problema maior é a mosca, porque a mosca aumenta muito a mão-de-obra, por que você tem que ensacar.

A controvérsia em torno do fungo Venturia inaequalis foi evidenciada primeiramente quando, em 2004, um dos primeiros anos em que se começou a colher maçã agroecológica, a sarna da macieira tornou-se uma das principais responsáveis pelas perdas de produção dos pomares convencionais. Dividia o título com fatores geralmente considerados externos aos pomares, como as intempéries, as geadas, o granizo e os baixos preços da maçã. A sarna geralmente está no âmbito interno do pomar e, se não é a única suscetível de controle dentre os fatores mencionados anteriormente, é sobre o que, com mais frequência, exigiu-se o pronunciamento dos técnicos, pois se vincula diretamente às formas de produção.

Foi isso o que aconteceu nessa safra, quando os engenheirossociólogos aproveitaram para expor as vantagens dos seus métodos no Jornal Carucaca. Esse jornal havia sido criado pouco antes, no ano de 2003, pelos movimentos sociais em São Joaquim. A primeira 
edição do Jornal Carucaca foi lançada em setembro/outubro pelas organizações criadas e/ou conquistadas pelo grupo que fundou a Credineve. Nesse momento, a Credineve já havia mudado a denominação para Cresol São Joaquim, e, além da criação da Econeve, haviam sido criadas uma cooperativa de produtores de batata (Coopercruzeiro) e uma rádio comunitária (Rádio Quebra-Gelo) e havia sido conquistado o Sindicato dos Trabalhadores Rurais. Além dessas organizações, é também responsável pelo expediente do jornal, na primeira edição, o Movimento de Mulheres Agricultoras. É por meio desse jornal que essas organizações procuraram se expressar. Como o primeiro editorial dizia:

O Carucaca é a realização de um desejo das entidades responsáveis por sua publicação de verem impressas suas idéias, objetivos, ideais e atividades. Não temos a pretensão de sermos os donos da verdade mas propor e discutir os temas expostos. Temos um ponto de vista e gostaríamos de trocar idéias com nossos associados, divulgar melhor o nosso trabalho e receber seus comentários e críticas. Como toda a publicação que está começando prometemos que iremos acertando os passos durante a caminhada. Mas nesta tarefa é necessário contar com vocês pois as entidades são aqueles e daqueles que as integram. Sejam Bem Vindos! $!^{19}$

Com esse veículo, criado para reverberar as opiniões dos movimentos, dentre elas as de seus engenheiros-sociólogos, na edição número 08 (novembro 2004/fevereiro 2005) do Jornal Carucaca, o editorial apontava "o quadro do desastre" diante da chamada epidemia da sarna, como foi qualificada por técnicos da estação experimental da Epagri. Segundo o editorial, essa epidemia completava o quadro dos desastres que acometiam aquela safra: preços baixos, geada e granizo. Diante disso, o editorial propunha um caminho: "a mudança dos modelos que norteiam a nossa agricultura", que é propriamente a proposta da agroecologia. Além disso, o jornal entrevistava os engenheiros-sociólogos, também produtores de maçã

${ }^{19}$ Editorial. Jornal Carucaca, São Joaquim, setembro/outubro de 2003, p. 2. 
agroecológica, para que oferecessem respostas ao controle da sarna.

Foram entrevistados o agrônomo Marcos Martini, o mesmo que havia sido contratado pela Credineve no início do processo de estímulo à produção de maçã agroecológica, e um integrante da Econeve, Silvio da Costa, técnico agrícola. Na entrevista, ambos afirmaram que a sarna está presente nos pomares, mas que, em condições de equilíbrio nutritivo das plantas, como é o caso dos seus pomares agroecológicos, a incidência é muito pequena. Além disso, nos seus pomares, contribuem para diminuição da incidência de sarna o controle biológico, com o uso de outros fungos, e outras práticas de manejo. Em contrapartida, a sarna tende a tornar-se um problema quando o desequilíbrio é provocado por adubações que estimulam um crescimento rápido da planta, o que acontece geralmente na produção convencional, casos em que o pomar fica predisposto à ocorrência da sarna devido à elevação desta.

Essa polêmica travada em torno da sarna, a qual não era o problema crucial da produção agroecológica, é importante para analisar como as considerações sobre a tecnologia não estão deslocadas de outras sobre a sociedade, como destacou Callon (1997). Nesse caso, o editorial do jornal já anunciava que o caminho pretendido era o da mudança de modelo que norteia a agricultura. O modelo pretendido aqui é aquele que as organizações responsáveis pelo jornal postulam, isto é, fundamentado em uma perspectiva agroecológica.

Se os engenheiros-sociólogos da maçã agroecológica deram respostas melhores, pelo menos no plano discursivo, ao controle da sarna, o mesmo não pode ser dito em relação à mosca-da-fruta. Como argumentado anteriormente, há, parcialmente, respostas para o controle da mosca, mas que ainda não se tornaram suficientes. A mosca Anastrepha fraterculus tornou-se um dos obstáculos mais importantes no caminho dos movimentos que propunham um novo modelo de agricultura, especialmente por meio da produção agroecológica de maçã, em São Joaquim.

Nos termos dos produtores, a mosca não os deixou trabalhar. É o que se vê no relato a seguir de um entrevistado, Alceu Parente, que tentou produzir maçã agroecológica. Ele tinha o interesse de abandonar a produção convencional com controle químico, sendo 
uma das pessoas que se envolveu desde o início com as pastorais da Igreja Católica. Teve contato com o agrônomo da Epagri, Elvio Peruchi, e com outra figura importante do movimento agroecológico, Delvino Magro, mas não conseguiu trabalhar com a produção de maçã agroecológica:

Eu não trabalhei muito tempo. Eu converti meu pomar dois anos, mas não deu pra trabalhar por causa da mosca. [...] a gente queria converter os pomares pra que se trabalhasse só na ecologia. A gente tentou. Tem que ser dois anos que não pode jogar química nenhuma. E a gente conseguiu manter naqueles dois anos. No sacrifício, por aqui não teve apoio. Você tem que ter muito apoio [...] Mas não tivemos apoio de ninguém. Era feito cada um pra si. $\mathrm{O}$ apoio que tinha era da Epagri [...]. O Peruchi dava aquele incentivo ali. Aí nós começamos trabalhar com o Magro. O Magro, era o que começou trabalhar o Supermagro, o nome dele era Magro, lá de Vacaria parece... de Ipê! Deram o nome de Supermagro e a gente combatia a sarna com esse tratamento. Então a gente não tem uma história muito grande porque a gente não ficou muito tempo na ecologia.

O mesmo aconteceu com outro entrevistado, que hoje é membro do Sindicato dos Trabalhadores Rurais (STR), Saulo Barbosa. A mosca não o permitiu trabalhar com a produção de maçã agroecológica:

Foi trabalhado uns 3 ou 4 anos e a dificuldade é que a nossa região lá é muito mato. Daí muita goiaba. Então ficou difícil de controlar foi a mosca [...]. E o que aconteceu: foi um ano muito difícil de conseguir muda, nós plantamos só gala. E a gala ali na nossa região é mais difícil de controlar ainda [...]. Sarna e as outras coisas foi conseguido controlar tudo. A dificuldade foi a mosca.

Na linguagem dos entrevistados, trabalhar significava completar o que havia sido feito em termos de mobilização política, de organização na Econeve e nas demais entidades e de aprendizado em cursos e testes práticos. Enfim, significava completar o deslocamento que havia sido feito da posição inicial de produtor de maçã convencional, 
isto é, tornar-se produtor de maçã agroecológica. Essa incompletude que, para esses agricultores, significa não trabalhar com a produção agroecológica de maçã está em consonância com a afirmação de Callon (1997), de que, para os engenheiros-sociólogos, os argumentos sofisticados e as teorizações não bastam. Esse momento chega quando, "se um engenheiro-sociólogo deve demonstrar que tem razão, tem que criar um novo mercado; o sucesso se mede pela quantidade de lucro obtido (Callon, 1997, p. 90 [tradução nossa])". As palavras podem assustar, mas, como arremata Callon (1997, p. 90 [tradução nossa]), "esta é, em toda sua simplicidade e crueza, a prova da verdade".

\section{CONCLUSÕES}

A produção de maçã em Santa Catarina e no Brasil teve um desempenho significativo em um período de aproximadamente quarenta anos, de modo que o Brasil passou a ter capacidade suficiente para abastecer a população com a fruta e também para exportar. Porém, o setor macieiro enfrenta um conjunto de questões que é comum a outros setores do chamado agronegócio: a busca por padrões de produção menos concentradores de riqueza e de poder e menos agressivos ao meio ambiente e à saúde humana.

Diante disso, neste estudo, analisou-se, em São Joaquim, o surgimento de uma experiência nesse sentido, que, em grande medida, não pode ser entendida como um desdobramento do setor macieiro, mas como uma contraposição a este e tudo que representa a "modernização da agricultura". Essa experiência ocorreu com a organização dos movimentos sociais em São Joaquim, que teve na Igreja Católica a principal base de apoio em seus momentos iniciais. Como se procurou mostrar, os padres ocupam papel-chave na conexão entre distâncias sociais, que se confundem ou não com distâncias geográficas, culturais, simbólicas e econômicas. Viu-se que estes tiveram um papel importante na organização do grupo que deu os primeiros passos para a criação de uma cooperativa de crédito, principalmente por meio do estudo em grupo e de reuniões com o objetivo de procurar saídas para aquilo que se vislumbrava como algo a ser mudado. 
No campo da agroecologia, a ação dos padres ganhou reforço de outra figura-chave: um técnico do Escritório Local da Epagri, o que desafiou a institucionalidade estabelecida. A Epagri como um todo, e também São Joaquim, é reconhecida como uma das responsáveis pela modernização da agricultura. No entanto, um técnico dessa empresa é um dos principais responsáveis por provocar uma significativa alteração nos rumos dessa modernização ao incluir na Epagri uma leva de agricultores familiares. Além disso, ele contribuiu fundamentalmente para ameaçar, ainda que de forma sutil, a hegemonia da moderna agricultura, com a produção agroecológica de maçã. O importante a reter aqui é que existe uma permeabilidade nas instituições, fato que é visível como a cristalização de redes sociais (Granovetter, 1992).

A ONG de atuação regional também tem contribuição crucial no processo que estudado neste artigo, pois constituiu uma forte ponte com os movimentos fora de São Joaquim, em outras regiões do estado e do país, dando origem a uma relação de duradoura qualidade. Ela envolve princípios sedimentados sobre o que seria um modelo de agricultura alternativo ao da modernização, entre outros que foram levantados ao longo deste texto.

A produção agroecológica que se estabeleceu em São Joaquim foi acompanhada de perto por esta ONG e pelo técnico da Epagri. Ambos forneceram apoio na forma de organização de cursos, experimentações e viagens para conhecer outras experiências e, também, na organização da cooperativa Econeve. Aqueles agricultores que estavam predispostos a buscar essa produção alternativa à moderna agricultura tiveram essa oportunidade. Vale ressaltar a ação da ONG e do técnico reforçada pela decisão da então Credineve em estimular a agroecologia no município.

Entretanto, uma dificuldade técnica se interpôs no caminho: a dificuldade em conter os danos causados pela mosca-das-frutas. O único método de controle disponível, sem o uso de produtos químicos, é o ensacamento dos frutos. Contudo, isso coloca os produtores em uma situação complicada por aumentar os custos de produção, sem saber se haverá condições de cobri-los com a venda. Essa situação interrompeu o que seria, para os produtores, a complementação da condição de agricultor agroecológico, já que trabalhar com agroecologia seria possível 
se a produção pudesse ser realizada no mercado. A Econeve passou por altos e baixos desde então, e isso aponta para questões mais amplas em torno da construção social dos mercados agroecológicos, as quais vão além do estabelecimento de laços fortes e fracos ${ }^{20}$.

Por fim, neste artigo, demonstrou-se que, além de objetivos políticos, expressos em diferentes maneiras discursivas, os movimentos sociais são constituídos com base na articulação de diferentes relacionamentos sociais (familiares, amigos, vizinhos etc.), os quais se tornam mais complexos à medida que seu alcance é ampliado. A partir do caso analisado, pôde-se observar o modo como os movimentos sociais no município de São Joaquim se constituíram em consonância com o que acontecia em âmbito nacional, destacadamente no que diz respeito à incorporação da questão ecológica.

Padres e técnicos tiveram papel fundamental junto a agricultores familiares na formação dessas redes de movimentos sociais. No entanto, um problema de ordem técnica se interpôs, fazendo com que fosse diminuído o número de componentes iniciais da Cooperativa Econeve, a organização especificamente voltada para a agroecologia dos movimentos sociais em São Joaquim. Todos os envolvidos estavam cientes das dificuldades técnicas, tendo buscado o aprendizado e as experimentações possíveis para resolvê-las. Resta saber o que seria possível se as respostas técnicas tivessem sido encontradas, o que talvez possa vir a acontecer algum dia.

\section{REFERÊNCIAS}

ALMEIDA, J. Agroecologia: paradigma para tempos futuros ou resistência para o tempo presente? Desenvolvimento e Meio Ambiente, $\mathrm{n}^{\circ}$. 6, pp. 29-40, jul.-dez. 2002.

ANDRIGUETO, J. R. \& KOSOSKI, A. R. Desenvolvimento e Conquistas da Produção Integrada de Frutas no Brasil. In: Palestras do II Simpósio Nacional do Morango; I Encontro de Pequenas Frutas e Frutas Nativas do Mercosul, Pelotas, 2004 / Editores Maria do Carmo Bassols Raseira et al. Pelotas: Embrapa Clima Temperado, 2004. 296p.

\footnotetext{
${ }^{20}$ Algumas dessas questões foram abordadas em outros trabalhos, ver Comunello (2012; 2013).
} 
ANUÁRIO DA FRUTICULTURA BRASILEIRA. Santa Cruz do Sul: Gazeta Santa Cruz, 2008.

BOLlER, E.; LENTEREN, J.; DELUCCHI, V. (Eds.). International Organization for Biological Control of Noxious Animals and Plants. History of de first 50 years (1956 - 2006). IOBC - OILB. Zürich, 1 November/2006.

BRANDT, A. Criação da Sociedade Agrícola Fraiburgo (Safra) e o início da pomicultura em Fraiburgo - SC, na década de 1960. Revista Discente Expressões Geográficas. Florianópolis-SC, n 01, pp. $27-$ 41, junho/2005.

BRDE - Banco Regional de Desenvolvimento do Extremo Sul. Agência de Porto Alegre. Superintendência de Planejamento. Cadeia produtiva da maçã: produção, armazenagem, comercialização, industrialização e financiamentos do BRDE na região sul do Brasil. Porto Alegre: BRDE, 2005. 65 p.

CALLON, M. Society in the Making: The Study of Technology as a Tool for Sociological Analysis. In: BIJKER, W. E.; HUGHES, T. P. and PINCH, T. F (Eds.). The Social Construction of Technological Systems: New Directions in the Sociology and History of Technology. Massachusetts/London: The MIT Press. 6a Ed., 1997 [1989], pp. 83-103.

COMUnEllo, F. J. Movimentos Sociais, Agroecologia e Circuitos no Capitalismo: Ruris - Revista do Centro de Estudos Rurais. Vol. 5, no. 2. Campinas: Unicamp/IFCH, 2012 (no prelo).

. Produto orgânico de produção agroecológica: a sensibilidade jurídica dos produtores agroecológicos. Revista Extensão Rural, DEAER-CCR - UFSM, Vol. 20, nº 1, 2013, pp. 69-80.

DIAS, M. M. As ONGs e a construção de alternativas para o desenvolvimento rural: um estudo a partir da Assessoria e Serviços a Projetos em Agricultura Alternativa (AS-PTA). Tese (Doutorado em Ciências Sociais) Programa de Pós-Graduação em Ciências Sociais, Universidade Federal Rural do Rio de Janeiro, CPDA/ UFRRJ, Rio de Janeiro, 2004, 207p.

FIORAVANÇO, J. C. Maçã brasileira: da importação à auto-suficiência - a tecnologia como fator determinante. Informações econômicas. SP, Vol. 39, n'.3, 2009, pp.56-67.

GIBBON, P.; BAIR, J.; PONTE, S. Governing global value chains: an 
introduction. Economy and Society, Vol. 37, n ${ }^{\circ}$ 3, 2008, pp.315-338.

GRANOVETTER, M. The Strength of Weak Ties. American Journal of Sociology. Vol. 78, 1973, pp.1360-1380.

. The Strength of Weak Ties: A Network Theory Revisited. Sociologial Theory, Vol. 1, 1983, pp.201-233.

Economic Institutions as Social Constructions: A Framework for Analysis. Acta Sociologica. Vol. 35, 1992, pp.03-11.

. Ação Econômica e Estrutura Social: O Problema da Imersão. RAE-eletrônica. Vol. 6, nº. 1. Art. 9. Janeiro-junho, 2007.

KLANOVICZ, J.; NODARI, E. Das Araucárias às Macieiras: transformações da paisagem em Fraiburgo, Santa Catarina. Florianópolis: Insular. 2005.

KLANOVICZ, J. Natureza corrigida: Uma História Ambiental dos Pomares de Macieira No Sul do Brasil (1960-1990). Tese (Doutorado em História) Programa de Pós-Graduação em História, Universidade Federal de Santa Catarina, Florianópolis, SC, 2007, 311p.

LUZZI, N. O debate agroecológico no Brasil: uma construção a partir de diferentes atores sociais. Tese (Doutorado em Ciências Sociais) Programa de Pós-Graduação em Ciências Sociais, Universidade Federal Rural do Rio de Janeiro, CPDA/ UFRRJ, Rio de Janeiro, 2007, 194p.

PEREIRA, J. A. Percepção do uso do solo e desenvolvimento rural: um estudo de etnopedologia no Planalto Sul de Santa Catarina. Dissertação (Mestrado em Ciências do Solo) Programa de PósGraduação em Ciências do Solo, Universidade do Estado de Santa Catarina, CAV/UDESC, Lages, SC, 2004.

RIBEIRO, L. M. Incentivos para certificação da qualidade no sistema de Produção Integrada de Frutas (PIF): um estudo de casos na cadeia produtiva da maçã. Dissertação (Mestrado em Engenharia de Produção) Programa de Pós-graduação em Engenharia de Produção, Universidade Federal de São Carlos, São Carlos, SP, 2005.

SCHMIDT, W. O setor macieiro em Santa Catarina: formação e consolidação de um complexo agroindustrial. Dissertação (Mestrado em Ciências Sociais) Programa de Pós-Graduação em Ciências Sociais, Universidade Federal Rural do Rio de Janeiro, CPDA/UFRRJ, Itaguaí, RJ, 1990. 
SIMIONI, F. J.; PEREIRA, L. B. Cadeia agroindustrial da maçã: uma análise da estrutura de governança sob a ótica da economia dos custos de transação. S/D. Disponível em www.sober.org.br/ palestra/12/04023.pdf Acessado em 06/01/2010.

STEINER, P. A sociologia econômica. São Paulo: Atlas, 2006.

SWEDBERG, R. Market as social structure. In: The Handbook of Economic Sociology. New Jersey: Princeton University Press, 1994, pp.255 -282 .

. Sociologia econômica: hoje e amanhã. Tempo Social, Revista de Sociologia da USP. Vol.16, no. 2, pp.7-34, 2004.

Recebido: 15/03/2014.

Aprovado: 03/06/2014. 